\title{
Stage IIB Pancreatic Cancer AJCC v8
}

National Cancer Institute

\section{Source}

National Cancer Institute. Stage IIB Pancreatic Cancer A/CC v8. NCI Thesaurus. Code C134927.

Stage IIB includes: (T1, N1, M0); (T2, N1, M0); (T3, N1, M0). T1: T umor measuring $2 \mathrm{~cm}$ or less in greatest dimension. T2: T umor measuring more than $2 \mathrm{~cm}$ and $4 \mathrm{~cm}$ or less in greatest dimension. T3: Tumor measuring more than $4 \mathrm{~cm}$ in greatest dimension. N1: Metastasis in one to three regional lymph nodes. M0: No distant metastasis. (AJCC 8th ed.) 